\title{
The Legislative Development of the Guardianship System for Minors
}

\author{
Lishan Huang ${ }^{1, a}$ and Xin Tang ${ }^{2, b}$ \\ ${ }^{1}$ Bauhinia apartment, Hainan University, Meilan District, No.58, Renmin Avenue, Haikou City, \\ Hainan Province, China \\ ${ }^{2}$ Bauhinia apartment, Hainan University, Meilan District, No.58, Renmin Avenue, Haikou City, \\ Hainan Province, China \\ a1611021604@qq.com, ${ }^{b} 1370409927 @ q q . c o m$
}

\begin{abstract}
Keywords: minors, guardianship system, the development of social legislation
\end{abstract}
\begin{abstract}
Minors are the future and hope of the nation that their sound growth is vital to the stability and development of society. The development and perfection of the guardianship system of minors will help care and protect them. Therefore, the author mainly analyzes the necessity and developmental characteristics of the system. Through which we can find that application of the principle of autonomy in the guardianship system for minors, the state and society's reasonable intervention, the affirmation of the dual attributes of guardian's rights and obligation and other characteristics are reflected in the principle of greatest interests of minors. Finally this article put forward the legislative recommendations of the juvenile guardianship system.
\end{abstract}

\section{Introduction of Guardianship of Minors}

Guardianship system is originated in the Roman law. "Law of the Twelve Tables" puts forward the guardianship system for the first time. Afterward the countries of the two legal systems developed their own guardianship system. Countries of the civil law system that is represented by France and Germany adopt parental authority and guardianship parallel system, strictly distinguishing between parental guardianship and others' guardianship. That is, it implements the narrow sense of guardianship, hence minors' guardians just refer to someone except their parents. Differently, countries of the Anglo-American legal system that is represented by the United Kingdom and the United States don't distinguish between parental authority and guardianship, in other words, it employs a mode of broad guardianship, its' guardians including parents. Chinese design of the guardianship system seems to follow the Anglo-American law system, not strictly distinguish between parental authority and guardianship, parents are the legal guardian of minors.

With the development of economy, culture, politics and so on, the guardianship system of minors has been continuously improved in China, as of now, having included statutory guardianship, arbitrary guardianship and designated guardianship. Nevertheless, due to the complexity of social relations, it remains to be improved in the conditions of application, the duties and rights of guardians, etc.

\section{The Necessity for the Establishment of Minors Guardian System}

China, a country of large population, whose number of minors is also fairly large. Due to the psychological and physical immaturity, minors' self-protection capacity is lacking, and their legitimate rights and interests can easily be ignored or infringed, thus every country protect minors 
through various legal systems and policy guidelines around the world. Civil law is a more than humanistic legal norms, for Montesquieu once said, "in the civil law of motherly eyes, each individual is throughout the country." As a vulnerable group without civil capacity, minors are required to protect their legitimate rights and interests through special remedies. The guardianship system is an extremely important civil legal system established by the state to protect minors and safeguard their legitimate rights and interests. Currently, developed countries have established a mature and operable guardianship system, and the protection for minors has been the consensus of the world.

Family is the first protective layer of minors, as growing minors spent the majority of the time at home, parents have a profound influence on the physical and mental health of minors, the quality of education and the development of ideal personality, etc. The guardianship system is the core of family protection, and the guardian's effective supervision is both based on emotion and fulfilling their statutory duty. Once the guardian neglects otherwise harms the duty of guardianship, the growth of minors and even the stability and development of society will be adversely affected. In recent years, we are shocked by the news reports of "Nanjing child abuse case", "girl starvation event" and so on, additionally, a large number of unsupervised left-behind children come into being due to parents out for work or other circumstances. Their encounter has aroused widespread concern in the public, but also makes the legal people continue to reflect on our country's juvenile protection system, and the development and improvement of guardianship system is undoubtedly important for the protection of minors and even the social progress.

\section{The Development of the Guardianship System for Minors}

First of all, with the increasing call on human rights, the guardianship system as a civil legal system more emphasizes the principle of autonomy. The root of the principle of autonomy is the "freedom of contract" advocated by western countries, that is, the parties shall have the right to establish otherwise terminate their rights and obligations in accordance with their personal wishes. The application of the principle of autonomy in the guardianship of minors is reflected in the guardianship by testament and by entrustment, and the parents are likely to appoint the most suitable guardian for their minor children through these two means of guardianship. In addition, "the maximization of the interests of minors" is also a manifestation of the principle of autonomy. The Convention on the Rights of the Child, adopted by the United Nations General Assembly in 1989, formally established the principle of the best interests of the child, hereafter China accedes to the Convention and becomes one of its Contracting States in 1991. Consequently, this principle must be taken seriously in the legislation of the protection of minors.

"The guardianship system is set up to protect people who are ill-advised and take into account the safety of transactions" [1]. The previous guardianship system focused on maintaining social security and order, often limiting the expression of individual freedom. With the continuous penetration of the principle of "maximization of the interests of minors" in legislation and practice, the current guardianship system demonstrates the humanistic spirit of civil law. "Humanistic spirit carries forward the subjectivity and value of human beings and the equal respect and care for human rights" [2]. The interests of the ward are the first in the guardianship of the minors, although capacity is limited, their personal will should still be respected. The future development of the guardianship system will keep pace with the times, in order to maximize the protection of the interests of the guardian as the core, arbitrary guardianship system will continue to improve and its status in the guard system will also be enhanced. 
At the same time, the dual attributes of the guardianship will be ulteriorly affirmed. It is clear that the concept is one-sided that the guardianship system merely protects the rights of the ward and don't give any benefit to the guardian. Specifically, on the one hand, the guardian has the legal duty to protect the ward's personal rights, property rights and other legitimate rights and interests. When the guardian fails to perform his duties or infringe upon the lawful rights and interests of the guardian, he shall bear legal liability. On the other hand, the guardian's performance of guardianship is a statutory right, that is, the law gives the guardian the right to exclude the illegal deprivation or damage of others. The guardian also enjoys rights what are like the right to claim remuneration, take the Swiss Civil Code for example, which clearly stipulates that the guardian has the right to request remuneration. Our legislation can refer to the relevant provisions, clear the guardian's remuneration claims in future. It is noteworthy that guardianship is also limited, for example, only when the guardian maintains the interests of the guardian, can he dispose the property of the ward in China. This limit once again embodies the legislative characteristics of guardianship that the minors' interests first.

Furthermore, the intervention of state and society will be more reasonable. Although guardianship is a legal system of civil law, in order to ensure the enforcement of the law, to maximize the realization of the purpose of protection of minors, the state and society are also involved in the guardianship system. For instances, in Germany, the guardian is usually determined by a special guardian court, and the guardian's election is subject to legal procedures, besides, it sets up the custodial supervisor. And China in accordance with the circumstances that qualified guardians are absent, stipulating the civil affairs department or the residents' committee and the villagers' committee of the place where the guardian is domiciled as a guardian, etc. State and society are responsible for the guardianship system, but there is a limit to the state and society's intervention in guardianship of minors so that they are required to respect the true wishes of the ward and to appoint a guardian for the minors according to the principles that are most favorable to the ward. Whereby the state and society as a supplementary role in the subject of guardianship can ensure that minors are always under the proper protection of the guardianship system. However, it is undeniable that there are many deficiencies of minors guardianship system in China, such as we set the main body of the oversight, but not clear the competent departments, lest the units may emerge the phenomena of prevarication with each other. While there are no detailed rules for the division and cooperation among various functional departments [3]. Therefore, the state and society intervention in the guardianship of minors should move in a more reasonable direction in the civil legislation in future.

\section{Legislative Improvement of Guardianship System for Minors}

Through the several points that development of juvenile guardianship system listed above, it is not difficult to find that the principle of maximizing the interests of minors is everywhere. In order to ensure minors to be taken good care, the legislators set up a series of guardianship systems in different legal norms, so that the minors who in different living conditions can be under the appropriate guardianship. And in granting the guardian a certain right, it also limits the exercise of rights, thereby preventing the right of guardianship from being abused and increasing their prudence and sense of responsibility. Although the legislation for revoking the guardianship of the unqualified guardian is relatively perfect, it is often difficult for the relevant organizations and individuals to find when the guardianship is improperly exercised because of the concealment of the family, so much so that the interests of minors cannot be timely and effective protection. Therefore, the author 
believes that the future legislation can further give more rights to the relevant organizations and individuals, such as the right of regular investigation. At the same time, it is necessary to clarify their duties. When they are slack to fulfill their obligations and fail to timely discover that the rights and interests of minors were violated, they should bear the legal responsibility. The other thing that needs to be emphasized is, future legislation should continue to adhere to the principle of maximizing the interests of minors, in particular, to arbitrary guardianship, in respect of parental guardianship by testament and by entrustment of the same time, to consider whether the person has a guardian qualification, whether to provide a good growth environment for minors and whether minors are willing to be taken care of and other factors. To ensure respect for the autonomy of parents will be more conducive to the growth and development of minors. Currently, there are a large number of phenomena that guardians cannot be better to fulfill the duties of guardianship; therefore, the perfection of arbitrary guardianship system will reduce even avoid the minor embarking on the road of illegal or criminal due to the lack of guardianship, to avoid making them live in a harsh living environment by the guardian who is designated by parents' negligence, and thus promote the protection of human rights and social stability.

In order to ensure the effective implementation of the guardianship system, the perfection of the supervisory mechanism is indispensable. It can set up the guardian supervisor by legislation and execute the mandatory reporting system, when the supervisor is negligent in performing the supervisory duty, he must undertake certain legal liability. The main duties of the supervisory supervisor are to confirm whether the guardian faithfully fulfills his duty, and when his guardianship behaviors in violation of the law or infringe upon the interests of the minors, reporting to the relevant units in time. Apart from when the guardian is disqualified, the supervisor should find a new guardian for minors to avoid being in the state of unattended. Moreover, a special public authority can be established or an organ can be designated to take charge of the supervision affairs. Through the supervision of both private and public rights, we can ensure that the guardian is under normal guardianship.

\section{Conclusion}

The system of guardianship of minors is an extremely important system in modern civil law, not only relevant to the sound growth of minors but also the stability of social order. The development of the system is a process of continuously demonstrating human rights; the interests of minors are increasingly protected in the continuous improvement of legislation. In this process, the state and society play an important role. The conflict as well as coordination between public and private rights make the implementation of the guardianship system more powerful and guaranteed. At the same time, the principle of maximizing the interests of minors is also constantly being highlighted, and the guardian's duties and rights are also taken seriously in the legislation. The level of legislation in the guardianship of minors reflects the degree of human rights protection in a country to a certain extent, which reflects the responsibility and commitment of the people to social development. With the development of social economy, the social relations are more complicated. The guardianship system is required to adapt to the changes of social life. The study on the development of the guardianship system of minors is undoubtedly conducive to the advancement of the protection system of minors, improving their operability and applicability. 


\section{References}

[1] Zejian Wang. Civil Law General [M]. China University of Political Science and Law Press. 2002.103.

[2] Wenxian Zhang. Legal Philosophy Category Research (revised edition) [M]. China University of Political Science and Law Press. 2001.390.

[3] Yingping Ye. Study on the Legislation of Minors' Arbitrary Guardianship [J]. Modern Law Science. 201739 (5) 44-53. 